\title{
Knowledge of periconceptional folic acid use among pregnant women at Ain Shams University Hospital, Cairo, Egypt
}

W. Al-Darzi, ${ }^{1}$ F. Al-Mudares, ${ }^{1}$ A. Farah, ${ }^{1}$ A. Ali ${ }^{1}$ and D. Marzouk ${ }^{2}$

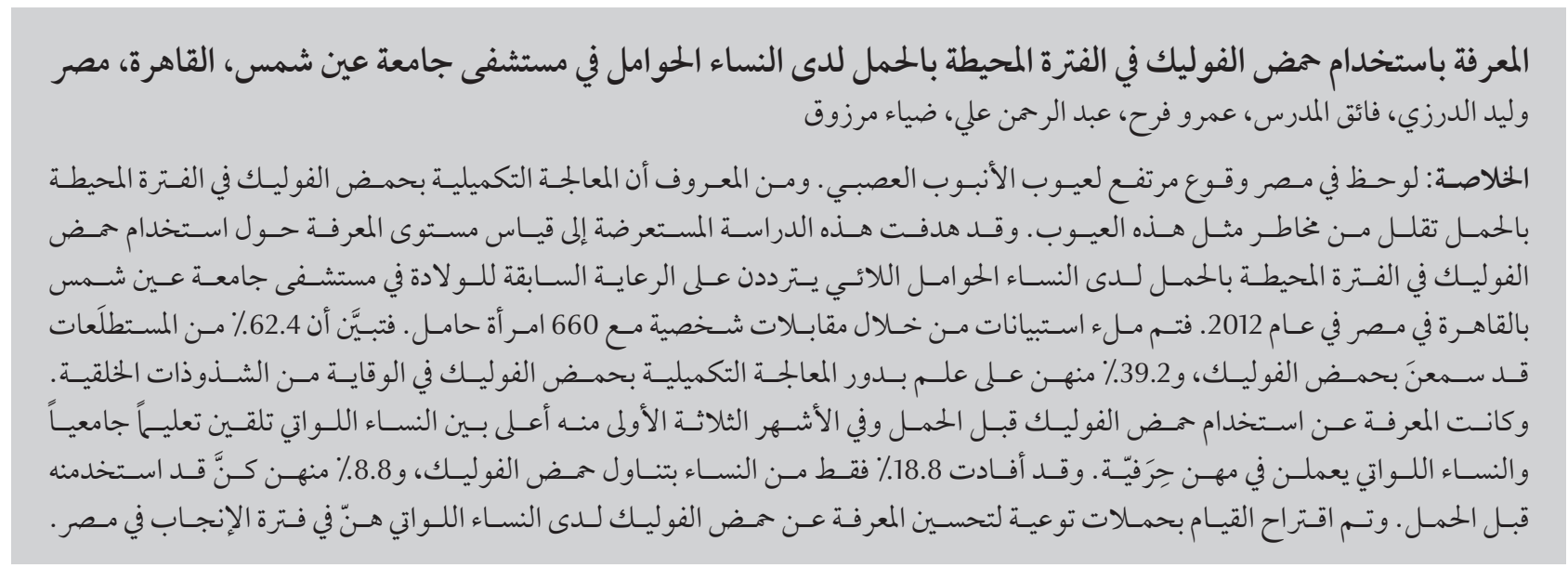

ABSTRACT Egypt has a high incidence of neural tube defects. Folic acid supplementation in the periconceptional period is known to lower the risk of such defects. This cross-sectional study aimed to measure the level of knowledge about periconceptional folic acid use among pregnant women attending for antenatal care at Ain Shams University Hospital, Cairo, Egypt in 2012. Questionnaires were filled through personal interviews with 660 pregnant women. Of the respondents, $62.4 \%$ had heard of folic acid and $39.2 \%$ knew about the role of folic acid supplementation in prevention of congenital anomalies. Knowledge about using folic acid before and in the first trimester of pregnancy was highest among university-educated women and those working in professional occupations. Only $18.8 \%$ of women reported taking folic acid, and $8.8 \%$ had used it before conception. Awareness campaigns are suggested to improve knowledge about folic acid among women in the childbearing period in Egypt.

Connaissances sur l'utilisation périconceptionnelle de l'acide folique chez des femmes enceintes à I'hôpital universitaire Ain Shams, au Caire (Égypte)

RÉSUMÉ En Égypte, l'incidence des malformations du tube neural est élevée. La supplémentation en acide folique durant la période périconceptionnelle est connue pour réduire le risque de telles malformations. La présente étude transversale visait à mesurer le niveau de connaissances sur l'utilisation périconceptionnelle de l'acide folique chez des femmes enceintes consultant à l'hôpital universitaire Ain Shams au Caire (Égypte) pour des soins prénatals en 2012. Des questionnaires ont été remplis pendant des entretiens individuels avec 660 femmes enceintes. Parmi les répondantes, 62,4 \% avaient entendu parler de l'acide folique et 39,2 \% connaissaient le rôle de la supplémentation en acide folique dans la prévention des anomalies congénitales. Les femmes ayant fait des études universitaires et celles exerçant une activité professionnelle possédaient les connaissances les plus élevées sur l'utilisation de l'acide folique avant et pendant le premier trimestre de grossesse. Seules 18,8 \% des femmes ont déclaré prendre de l'acide folique, et 8,8 \% y avaient eu recours avant la conception. Des campagnes de sensibilisation sont suggérées pour améliorer les connaissances sur l'acide folique chez les femmes en âge de procréer en Égypte. 


\section{Introduction}

Neural tube defects (NTDs) are birth defects of the brain and spinal cord that can cause death, or permanent damage to the nervous system (1). The most frequent forms of NTDs are spina bifida and anencephaly (2). Such defects are among the most common birth defects worldwide (3), occurring in an estimated 300000 newborns each year $(2,4)$. Evidence of the relationship between insufficient intake of maternal folic acid and the risk of NTDs led to the United States Public Health Service recommendation in 1992 that women with the capacity to become pregnant need to consume $400 \mu \mathrm{g}$ folic acid on a daily basis (5). The incidence of NTDs falls by $50 \%-80 \%$ when women consume folic acid supplements daily, and there is now a consensus that supplementation should begin not only during the first trimester but also earlier, before conception (6-8); this was supported by a cohort study in 1999 by Berry et al. (9).

In view of the benefits of consuming folic acid for women in the childbearing years, several studies have been conducted in different parts of the world to assess women's awareness of the role of folic acid in fetal development. In the United States of America (USA), there has been an increasing trend in the percentage of women who are aware of the benefits of folic acid, up to $85 \%$ (10), whereas in Qatar $53.7 \%$ of women had heard about folic acid and only $15 \%$ of them knew its role in preventing birth defects (11). With regard to preconceptional use of folic acid, a study conducted in Taipei among pregnant women showed that only $15.6 \%$ of them had taken folic acid before conception (12).

In Egypt, neurological disorders are the most common birth defects, with NTDs forming $10.2 \%$ of neurological disorders (13). One study found the incidence of NTDs in Egypt to be $1.38 \%$ (14), which is high compared with other parts of the world, where the reported incidence ranges from
$0.05 \%$ to $0.36 \%(2,15)$. To date, there had been very little evidence in the literature about knowledge and practice of folic acid use among pregnant women in Egypt. The aim of this study was to measure the level of knowledge about periconceptional use of folic acid among pregnant women at Ain Shams University hospital, Cairo, Egypt. The current study will provide a baseline description about folic acid knowledge which can be used to assess the need for awareness campaigns.

\section{Methods}

\section{Study design and sample}

This cross-sectional, observational study was conducted in the antenatal care (ANC) clinic at Ain Shams University Hospital, Cairo, Egypt. This is considered one of the main hospitals in north-east Cairo, receiving a variety of patients from different regions of Cairo and even from other governorates. Any pregnant women aged $18-45$ years who sought medical consultation at the ANC clinic were included. The diagnosis of pregnancy was confirmed by viewing patients' files, previous history, examination and investigations [previous urine beta-human chorionic gonadotropin ( $\beta \mathrm{HCG}$ ), blood $\beta \mathrm{HCG}$ or ultrasound]. Pregnant woman who were younger than 18 or older than 45 years were excluded. Data were collected by questionnaires from 670 pregnant women during the period from June to August 2012; 10 pregnant women did not give consent for participation in the study, giving a response rate of $98.2 \%$.

\section{Data collection}

An anonymous, standardized questionnaire was filled through an interpersonal interview. This included 15 questions about the following: sociodemographic data (age, residency, occupation, educational level); obstetric history (gravidity, previous ANC; number of ANC visits; gestational age); and folic acid knowledge and use (ever heard about folic acid before, from where she heard about it, recommended period of intake according to her knowledge, whether she took folic acid in the current pregnancy and if so when, benefits of folic acid intake, and different food sources of folic acid). The number of ANC visits in the current pregnancy was classified as sufficient or insufficient, according the recommendations of the Royal College of Obstetricians and Gynaecologists (16).

The validity of the questionnaire was tested by translating a pre-existing questionnaire (17) to Arabic language and comparing the findings of both questionnaires. The reliability of the questionnaire was evaluated by interviewing 20 patients from the inpatient clinic twice with different interviewers and separated by 5 days. The findings of both interviews were compared. After the pilot study, the questions were rearranged, modified by adding more choices or substituting open questions.

The questionnaire was written in the common Egyptian Arabic dialect and each interviewer followed the question structure strictly with agreed-upon alternative explanations. Each interview was conducted by one of the trained authors. The pregnant women were interviewed while they were waiting for their ANC visit, in a separate area from the other participants to ensure privacy and confidentiality. Participants who agreed to participate were interviewed regardless of whether if was their first or follow-up visit. The interviewers visited the ANC clinic 4 times per week for a 9-week period.

Verbal consent was taken from each participant $(n=660)$ before filling the questionnaire. The study protocol has been approved by the ethics committee of Ain Shams University. The questionnaire was developed by the authors of this study in consultation with the community department at Ain Shams University. Then it received ethical approval from 2 different faculty staff members. 


\section{Data analysis}

The collected data were revised, coded and tabulated using SPSS, version 15.0.1 for Windows. Quantitative continuous variables are expressed as mean and standard deviation (SD). Qualitative variables are expressed as frequencies and percentages. Student t-test was used to compare continuous variables between the 2 study groups. Chisquared and Fisher exact tests were used to examine the relationship between categorical variables. Both univariate and multivariate logistic regression analyses were done to examine the association of awareness and intake of folic acid supplements with selected sociodemographic and obstetric characteristics of the studied women. $P<$ 0.05 was considered as the cut-off value for significance.

\section{Results}

\section{Sociodemographic characteristics and folic acid knowledge}

Table 1 shows the sociodemographic characteristics of all the pregnant women in the study and of the women who had heard about folic acid before. From the total sample of 660 women, $412(62.4 \%)$ had heard about folic acid. Only 79 (12.0\%) women knew it was important to take folic acid before pregnancy and 53 (8.2\%) knew about taking it in both the preconception and 1st trimester periods. Out of the whole sample of women, 259 (39.2\%) mentioned its role in prevention of birth defects.

Out of the total sample of respondents, 124 (18.8\%) reported taking folic acid in the current pregnancy; 58 (8.8\%) had taken it before pregnancy and 80 (12.1\%) took it in the 1st trimester.

For the women who had heard about folic acid their main source of knowledge was the physician, reported by $92.0 \%$; other sources of knowledge were the family, nurses, pharmacists, media, books and the Internet (8.0\%). The highest knowledge rates about folic acid were found among women working in professional jobs (90.9\%). Women with university education $(88.3 \%)$ and of women with history of $\geq 6$ pregnancies $(84.4 \%)$ were the most aware about folic acid. The lowest knowledge rates were among illiterate women and those with only primary school educational $(25.0 \%$ and $35.6 \%$ respectively). When the participants who reported knowing about folic acid were asked about sources of folic acid, 92.0\% reported folic acid supplements, $2.9 \%$ fish, $1.1 \%$ liver and $4.0 \%$ green vegetables

The relationship between the sociodemographic characteristics of the pregnant women and their knowledge about the use of folic acid was analysed for 3 groups: those who knew about preconceptional use of folic acid $(n=$ 79), those who knew about 1st trimester use of folic acid $(n=324)$ and those who knew the recommended period of intake of folic acid, i.e. knew about folic acid intake during both the preconceptional and 1 st trimester periods $(n=54)$ (Table 2). Highly significant relationships between the educational level of pregnant women and their knowledge about folic acid intake were seen in all 3 groups $(P<0.01)$. Occupational status and number of previous pregnancies were significantly related to women's awareness of folic acid utilization preconception $(P=0.011$ and $P=0.0001$ respectively) and in both recommended intake periods $(P=0.004$ and $P=$ 0.046 respectively). Having a sufficient number of ANC visits for the current

\begin{tabular}{|c|c|c|c|c|}
\hline \multirow[t]{2}{*}{ Variable } & \multicolumn{2}{|c|}{ All women } & \multicolumn{2}{|c|}{ Heard about folic acid } \\
\hline & No. & $\%$ & No. & $\%$ \\
\hline Total & 660 & 100.0 & 412 & 62.4 \\
\hline \multicolumn{5}{|l|}{ Age group (years) } \\
\hline $18-24$ & 209 & 31.7 & 111 & 53.1 \\
\hline $25-29$ & 359 & 54.4 & 238 & 66.3 \\
\hline $30-34$ & 74 & 11.2 & 51 & 68.9 \\
\hline $35-45$ & 18 & 2.7 & 12 & 66.7 \\
\hline \multicolumn{5}{|l|}{ Education } \\
\hline Illiterate & 116 & 17.6 & 29 & 25.0 \\
\hline Primary school & 45 & 6.8 & 16 & 35.6 \\
\hline Preparatory school & 106 & 16.1 & 56 & 52.8 \\
\hline Secondary school & 299 & 45.3 & 228 & 76.3 \\
\hline University & 94 & 14.2 & 83 & 88.3 \\
\hline \multicolumn{5}{|l|}{ Job } \\
\hline Not working & 600 & 90.9 & 360 & 60.0 \\
\hline Skilled work & 27 & 4.1 & 22 & 81.5 \\
\hline Professional & 33 & 5.0 & 30 & 90.9 \\
\hline \multicolumn{5}{|l|}{ Gravidity (no.) } \\
\hline$\leq 2$ & 432 & 65.5 & 266 & 61.6 \\
\hline $3-5$ & 196 & 29.7 & 119 & 60.7 \\
\hline$\geq 6$ & 32 & 4.8 & 27 & 84.4 \\
\hline \multicolumn{5}{|c|}{$A N C$ visits in current pregnancy } \\
\hline Insufficient & 99 & 15.0 & 43 & 43.4 \\
\hline Sufficient & 561 & 85.0 & 369 & 65.8 \\
\hline
\end{tabular}

$n / a=$ not applicable $; A N C=$ antenatal care. 


\begin{tabular}{|c|c|c|c|c|c|c|c|c|c|}
\hline \multirow[t]{3}{*}{ Variable } & \multicolumn{9}{|c|}{ Knew about folic acid supplementation during: } \\
\hline & \multicolumn{3}{|c|}{ Preconception $(n=79)$} & \multicolumn{3}{|c|}{ 1st trimester $(n=324)$} & \multicolumn{3}{|c|}{ Both periods $(n=54)$} \\
\hline & No. & $\%^{\mathrm{a}}$ & $P$-value & No. & $\%^{\mathrm{a}}$ & $P$-value & No. & $\%^{\mathrm{a}}$ & $P$-value \\
\hline \multicolumn{10}{|l|}{ Age (years) } \\
\hline $18-24$ & 15 & 13.5 & 0.098 & 87 & 78.4 & 0.694 & 9 & 8.1 & 0.190 \\
\hline $25-29$ & 53 & 22.3 & & 187 & 78.6 & & 38 & 16.0 & \\
\hline $30-34$ & 7 & 13.7 & & 42 & 82.4 & & 5 & 9.8 & \\
\hline $35-45$ & 4 & 33.3 & & 8 & 66.7 & & 2 & 16.7 & \\
\hline \multicolumn{10}{|l|}{ Education } \\
\hline Illiterate & 1 & 3.4 & 0.002 & 15 & 51.7 & $<0.001$ & 0 & 0.0 & $<0.001$ \\
\hline Primary school & 1 & 6.3 & & 12 & 75.0 & & 1 & 6.3 & \\
\hline Preparatory school & 6 & 10.7 & & 36 & 64.3 & & 1 & 1.8 & \\
\hline Secondary school & 45 & 19.7 & & 189 & 82.9 & & 29 & 12.7 & \\
\hline University & 26 & 31.3 & & 72 & 86.7 & & 23 & 27.7 & \\
\hline \multicolumn{10}{|l|}{ Occupation } \\
\hline Not working & 63 & 17.5 & 0.011 & 280 & 77.8 & 0.486 & 40 & 11.1 & 0.004 \\
\hline Skilled work & 4 & 18.2 & & 18 & 81.8 & & 4 & 18.2 & \\
\hline Professional & 12 & 40.0 & & 26 & 86.7 & & 10 & 33.3 & \\
\hline \multicolumn{10}{|l|}{ Gravidity (no.) } \\
\hline$\leq 2$ & 39 & 14.7 & $<0.001$ & 206 & 77.4 & 0.101 & 27 & 10.2 & 0.046 \\
\hline $3-5$ & 28 & 23.5 & & 100 & 84.0 & & 21 & 17.6 & \\
\hline$\geq 6$ & 12 & 44.4 & & 18 & 66.7 & & 6 & 22.2 & \\
\hline \multicolumn{10}{|l|}{$\begin{array}{l}\text { ANC visits in current } \\
\text { pregnancy }\end{array}$} \\
\hline Insufficient & 5 & 11.4 & 0.164 & 29 & 65.9 & 0.029 & 3 & 6.8 & 0.191 \\
\hline Sufficient & 74 & 20.1 & & 295 & 80.2 & & 51 & 13.9 & \\
\hline
\end{tabular}

aPercentage of women in each sociodemographic and obstetric category who had heard about folic acid. $A N C=$ antenatal care

pregnancy was significantly related to knowledge of folic acid intake during the 1st trimester $(P=0.029)$.

\section{Univariate analysis}

Table 3 shows the univariate analysis of sociodemographic characteristics of the study women and their knowledge about folic acid intake. Knowledge about folic acid intake during the preconceptional period showed significant relationships with age group (25-29 years), university education level, professional occupation and history of $\geq 2$ pregnancies. Women with university education level were about 13-fold more aware about folic acid than illiterate women $(\mathrm{OR}=12.8,95 \%$ CI: 1.65-99.0), while specialist working women were 3 -fold more aware about folic acid than non-working women $(\mathrm{OR}=3.14,95 \% \mathrm{CI}: 1.44-6.85)$. Women who had a pregnancy history of $\geq 3$ were $1.8-4$.6 times more aware than women with history of $\leq 2$ pregnancies.

Secondary school/diploma and university levels of education were highly significantly associated with knowledge about folic acid intake during the 1st trimester. Women with secondary school and university educational level were more than 4-fold ( $\mathrm{OR}=4.52$, 95\% CI: 2.02-10.1) and 6-fold (OR = 6.11, 95\% CI: 2.33-16.1) more aware than illiterate women respectively. Sufficient ANC visits during the current pregnancy was significantly related to knowledge about folic acid, as women who had sufficient ANC visits during their current pregnancy were twice as aware about folic acid than those who had insufficient $A N C$ visits $(O R=2.09$, 95\% CI: 1.07-4.10).

The relationship of sociodemographic characteristics of the women with their knowledge about the both periods of folic acid intake showed very similar results as for knowledge about folic acid during the preconceptional period.

\section{Multivariate analysis}

The multivariate analysis of sociodemographic characteristics is shown in Table 4. The relationships between the women's knowledge of folic acid and their sociodemographic characteristics 


\begin{tabular}{|c|c|c|c|c|c|c|}
\hline \multirow[t]{3}{*}{ Variable } & \multicolumn{6}{|c|}{ Knew about folic acid supplementation during: } \\
\hline & \multicolumn{2}{|c|}{ Preconception } & \multicolumn{2}{|c|}{ 1st trimester } & \multicolumn{2}{|c|}{ Both periods } \\
\hline & $\begin{array}{c}\text { Crude OR } \\
(95 \% \mathrm{Cl})\end{array}$ & $P$-value & $\begin{array}{c}\text { Crude OR } \\
(95 \% \mathrm{CI})\end{array}$ & $P$-value & $\begin{array}{c}\text { Crude OR } \\
(95 \% \mathrm{CI})\end{array}$ & $P$-value \\
\hline \multicolumn{7}{|l|}{ Age (years) } \\
\hline $18-24$ & (Ref.) & & & & & \\
\hline $25-29$ & $1.83(0.98-3.42)$ & 0.057 & $1.01(0.59-1.75)$ & 0.967 & $2.15(1.00-4.63)$ & 0.049 \\
\hline $30-34$ & $1.02(0.39-2.67)$ & 0.971 & $1.29(0.55-3.01)$ & 0.560 & $1.51(0.51-4.50)$ & 0.458 \\
\hline $35-45$ & $3.20(0.86-12.0)$ & 0.084 & $0.55(0.15-1.99)$ & 0.363 & $2.27(0.43-12.0)$ & 0.335 \\
\hline \multicolumn{7}{|l|}{ Education } \\
\hline Illiterate & (Ref.) & & & & & \\
\hline Primary school & $1.87(0.11-32.0)$ & 0.667 & $2.80(0.73-10.8)$ & 0.134 & $1.87(0.11-32.0)$ & 0.667 \\
\hline Preparatory school & $3.36(0.39-29.3)$ & 0.273 & $1.68(0.68-4.18)$ & 0.264 & $0.51(0.03-8.45)$ & 0.638 \\
\hline Secondary school & $6.89(0.91-52.0)$ & 0.061 & $4.52(2.02-10.1)$ & $<0.001$ & $4.08(0.54-31.1)$ & 0.175 \\
\hline University & $12.8(1.65-99.0)$ & 0.015 & $6.11(2.33-16.1)$ & $<0.001$ & $10.7(1.38-83.5)$ & 0.023 \\
\hline \multicolumn{7}{|l|}{ Occupation } \\
\hline Not working & (Ref.) & & & & & \\
\hline Skilled work & $1.05(0.34-3.20)$ & 0.935 & $1.29(0.42-3.91)$ & 0.658 & $1.73(0.56-5.36)$ & 0.343 \\
\hline Professional & 3.14 (1.44-6.85) & 0.004 & $1.86(0.63-5.48)$ & 0.262 & $3.89(1.70-8.88)$ & $<0.001$ \\
\hline \multicolumn{7}{|l|}{ Gravidity (no.) } \\
\hline$\leq 2$ & (Ref.) & & & & & \\
\hline $3-5$ & 1.79 (1.04-3.08) & 0.035 & $1.53(0.87-2.71)$ & 0.141 & $1.90(1.02-3.52)$ & 0.042 \\
\hline$\geq 6$ & 4.66 (2.03-10.7) & $<0.001$ & $0.59(0.25-1.37)$ & 0.213 & $3.10(1.20-8.00)$ & 0.019 \\
\hline \multicolumn{7}{|l|}{$\begin{array}{l}\text { ANC visits in current } \\
\text { pregnancy }\end{array}$} \\
\hline Insufficient & (Ref.) & & & & & \\
\hline Sufficient & $1.96(0.75-5.16)$ & 0.171 & $2.09(1.07-4.10)$ & 0.032 & $2.25(0.67-7.53)$ & 0.189 \\
\hline
\end{tabular}

$O R=$ odds ratio $; C I=$ confidence interval; $A N C=$ antenatal care $;($ Ref. $)=$ reference category .

in the multivariate analysis were similar to those in the univariate analysis, except for occupational status which was not significant in multivariate analysis.

\section{Discussion}

The impact of NTDs is considered a global health-care issue affecting huge number of newborns each year (4). Fortunately, the risks of NTDs can be reduced by using folic acid before and during the 1st trimester of pregnancy $(6,8,9)$. In Egypt, the high incidence of NTDs (14) points to a need for prevention by increasing women's awareness of periconceptional use of folic acid. The present study at a tertiary care clinic in
Cairo, Egypt showed that $62.4 \%$ of the pregnant women surveyed knew about folic acid in pregnancy. Looking at different studies conducted in the Middle East, the level of awareness ranged from $46.6 \%$ to $85 \%(11,18,19)$. In Taiwan the awareness rate among pregnant women was 89.1\% (12). In a study in Kansas, USA, the level of general awareness about folic acid was $88 \%$ among women of childbearing ages (20). A small percentage of women in the present study had some university education $(14.2 \%)$ whereas in the Kansas study $65.6 \%$ of women had some college education or were college graduates (20), which might explain their higher general awareness level.

The present study demonstrated that the proportion of all participants who knew about the benefits of folic acid in prevention of birth defects was $39.2 \%$. This percentage is higher than in other nearby countries in the Middle East $(8.7 \%-14 \%)(11,18,21)$, but lower than in Israel and Abu Dhabi, United Arab Emirates (UAE) (46.6\%-77.7\%) $(19,22)$, which shows that there is room for improvement. When compared with Israel our women's knowledge about taking folic acid both preconception and in the 1 st trimester was considerably lower (Egypt: 8.2\%, Israel: 77.7\%) (19).

Although in the present study the nature of the women's occupation affected their knowledge about use of folic acid before conception, it was significant in univariate analysis but not in multivariate analysis, which suggests 


\begin{tabular}{|c|c|c|c|c|c|c|}
\hline \multirow[t]{3}{*}{ Variable } & \multicolumn{6}{|c|}{ Knew about folic acid supplementation during: } \\
\hline & \multicolumn{2}{|c|}{ Preconception } & \multicolumn{2}{|c|}{ 1st trimester } & \multicolumn{2}{|c|}{ Both periods } \\
\hline & $\begin{array}{l}\text { Adjusted OR } \\
(95 \% \mathrm{Cl})\end{array}$ & $P$-value & $\begin{array}{l}\text { Adjusted OR } \\
(95 \% \mathrm{Cl})\end{array}$ & $P$-value & $\begin{array}{l}\text { Adjusted OR } \\
(95 \% \mathrm{Cl})\end{array}$ & $P$-value \\
\hline \multicolumn{7}{|l|}{ Age (years) } \\
\hline $18-24$ & (Ref.) & & & & & \\
\hline $25-29$. & $1.42(0.72-2.81)$ & 0.313 & $1.04(0.57-1.88)$ & 0.906 & $1.69(0.73-3.87)$ & 0.218 \\
\hline $30-34$ & $0.71(0.24-2.11)$ & 0.536 & $1.44(0.55-3.77)$ & 0.461 & $0.99(0.28-3.45)$ & 0.983 \\
\hline $35-45$ & $2.07(0.46-9.38)$ & 0.343 & $0.68(0.17-2.77)$ & 0.589 & $1.58(0.25-9.96)$ & 0.628 \\
\hline \multicolumn{7}{|l|}{ Education } \\
\hline Illiterate & (Ref.) & & & & & \\
\hline Primary school & $1.94(0.11-35.0)$ & 0.653 & $2.66(0.66-10.8)$ & 0.171 & $1.85(0.10-33.4)$ & 0.676 \\
\hline Preparatory school & $3.00(0.33-27.2)$ & 0.329 & $2.11(0.82-5.44)$ & 0.124 & $0.47(0.03-8.12)$ & 0.605 \\
\hline Secondary school & $7.65(1.00-58.7)$ & 0.050 & $5.67(2.44-13.2)$ & $<0.001$ & $4.62(0.60-35.8)$ & 0.143 \\
\hline University & $15.33(1.88-124)$ & 0.011 & $7.23(2.52-20.7)$ & $<0.001$ & $13.1(1.59-108)$ & 0.017 \\
\hline \multicolumn{7}{|l|}{ Occupation } \\
\hline Not working & (Ref.) & & & & & \\
\hline Skilled work & $0.77(0.23-2.54)$ & 0.666 & $1.07(0.33-3.48)$ & 0.906 & $1.11(0.33-3.75)$ & 0.865 \\
\hline Professional & $1.53(0.61-3.84)$ & 0.370 & $1.03(0.31-3.47)$ & 0.959 & $1.40(0.53-3.74)$ & 0.499 \\
\hline \multicolumn{7}{|l|}{ Gravidity (no.) } \\
\hline$\leq 2$ & (Ref.) & & & & & \\
\hline $3-5$ & $2.17(1.18-4.00)$ & 0.013 & $1.73(0.93-3.23)$ & 0.083 & $2.30(1.13-4.67)$ & 0.021 \\
\hline$\geq 6$ & $6.23(2.37-16.4)$ & $<0.001$ & $0.61(0.24-1.57)$ & 0.307 & $4.83(1.59-14.7)$ & 0.006 \\
\hline \multicolumn{7}{|l|}{$\begin{array}{l}\text { ANC visits in current } \\
\text { pregnancy }\end{array}$} \\
\hline Insufficient & (Ref.) & & & & & \\
\hline Sufficient & $1.90(0.68-5.29)$ & 0.220 & $2.21(1.08-4.52)$ & 0.030 & $2.01(0.57-7.10)$ & 0.281 \\
\hline
\end{tabular}

$O R=$ odds ratio $; C I=$ confidence interval; $A N C=$ antenatal care $;($ Ref. $)=$ reference category.

that as a variable it has less influence than educational level or number of pregnancies. Knowledge about the use of folic acid during both the preconceptional and 1 st trimester periods was very high among women with university education, and increased significantly with the number of pregnancies.

In the present study $18.8 \%$ of the pregnant women reported consuming folic acid during the current pregnancy. In the UAE the percentage was much higher, at $68 \%(18,22)$, which may be due to the fact that the UAE government ANC facilities provided folic acid free of charge. Supplying folic acid supplements for all visitors to ANC clinics is likely to raise the percentage of females using them and hence decrease the incidence of NTDs. This is an important consideration for policy-makers. Besides the emotional, psychological and physical effects of spina bifida, the total cost of lifetime management of the cases who survive is high and causes a huge burden on the community (23). Further studies should be done to study the cost-benefit of providing folic acid free of charge in Egypt.

A study in Qatar demonstrated that the physician was the main source of women's knowledge about folic acid (63.4\%) (11), although in Taipei the percentage was $44.4 \%$ (12). Other sources of knowledge in those studies included newspapers, books, nurses, pharmacists and the family. Our study revealed that $92.0 \%$ of women knew about folic acid from the physician. This finding should be considered in folic acid promotion campaigns. Amtai et al. suggested that every family planning consultation and every child vaccination should be used as an opportunity to promote folic acid use (19). This is also applicable in Egypt, especially during visits for obligatory childhood immunizations. Another method of spreading folic acid awareness is through awareness campaigns, which could include posters, announcements in the media and sessions for high-school or even university students. These campaigns should educate women about foods that are rich in folic acid, in addition to encouraging the consumption of the 
recommended daily dose of folic acid supplements or as part of multivitamin tablets.

Fortification of foods with folic acid is another strategy for decreasing NTDs. Data has revealed an association between folic acid fortification and a decrease in the risk of NTDs (24). It is noteworthy that the fortification of some foods, including enriching cereals and grains with folic acid, was mandated in the USA since 1998 (25). After folic acid fortification was implemented the reduction in the prevalence of NTDs in the country was $23 \%$ (26).

There were some limitations that may have affected the study findings. First, the study may have been subjected to population bias, as the data were collected from only one health-care centre in Cairo, Egypt. Secondly, the study women were attending a tertiary health-care facility and they may not have had the same level of knowledge as women attending for ANC in primary or secondary health-care facilities. Thirdly, women below age 18 years and older than 45 years were not included in our sample and therefore our results might not accurately reflect the level of knowledge about folic acid in all women of childbearing ages. Finally, women were included regardless their previous number of ANC visits.

In conclusion, there is room for improvement regarding the knowledge about folic acid among women in the childbearing years in Egypt. The present study revealed that a small proportion of women were aware about the importance of preconceptional folic acid, and even fewer had consumed folic acid in the preconceptional period. Knowledge about folic acid intake was significantly higher among women with university education and high gravidity. Although doctors were the main source of knowledge, we suggest that health-care providers should be given guidelines about raising awareness of folic acid among women of reproductive age. Additionally, awareness campaigns about folic acid should be held, targeting women in the reproductive age groups. Further studies need to be conducted in Egypt to demonstrate the cost-benefit of providing folic acid supplementation free of charge to all women at ANC clinics and for a programme of food fortification with folic acid.

\section{Acknowledgements}

We thank Dr Waleed Salah El-Din, lecturer in the Department of Community, Occupational and Environmental Medicine, Ain Shams University, for his role in the statistical analysis in our research.

\section{Funding: None.}

Competing interests: None declared.

\section{References}

1. Campbell LR, Dayton DH, Sohal GS. Neural tube defects: a review of human and animal studies on the etiology of neural tube defects. Teratology. 1986 Oct;34(2):171-87. PMID:3535149

2. Cragan JD, et al. Surveillance for anencephaly and spina bifida and the impact of prenatal diagnosis-United States, 1985-1994. MMWR CDC Surveill Summ. 1995;44(4):1-13. PMID:7799912

3. Marks JD, Khoshnood B. Epidemiology of common neurosurgical diseases in the neonate. Neurosurg Clin N Am. 1998 Jan;9(1):63-72. PMID:9405765

4. Shibuya KMC. Congenital anomalies. In: Murray CJL, Lopez $A D$, editors. Health dimensions of sex and reproduction: the global burden of sexually transmitted diseases, HIV, maternal conditions, perinatal disorders, and congenital anomalies. Boston (Massachusetts): Harvard University Press; 1998. pp. 455-512.

5. Recommendations for the use of folic acid to reduce the number of cases of spina bifida and other neural tube defects. MMWR Recomm Rep.1992 Sep 11;41(RR-14):1-7. PMID:1522835

6. Wilson RD, Johnson JA, Wyatt P, Allen V, Gagnon A, Langlois $S$, et al.; Genetics Committee of the Society of Obstetricians and Gynaecologists of Canada and The Motherrisk Program. Pre-conceptional vitamin/folic acid supplementation 2007: the use of folic acid in combination with a multivitamin supplement for the prevention of neural tube defects and other congenital anomalies. J Obstet Gynaecol Can. 2007 Dec;29(12):1003-26. PMID:18053387

7. Wilson RD, Davies G, Désilets V, Reid GJ, Summers A, Wyatt $P$, et al.; Genetics Committee and Executive and Council of the Society of Obstetricians and Gynaecologists of Canada. The use of folic acid for the prevention of neural tube defects and other congenital anomalies. J Obstet Gynaecol Can. 2003 Nov;25(11):959-73. PMID:14608448

8. Wald N, et al.; MRC Vitamin Study Research Group. Prevention of neural tube defects: results of the Medical Research Council Vitamin Study. Lancet. 1991 Jul 20;338(8760):131-7. PMID:1677062

9. Berry RJ, Li Z, Erickson JD, Li S, Moore CA, Wang H, et al.; Collaborative Project for Neural Tube Defect Prevention. Prevention of neural-tube defects with folic acid in China. China-U.S. N Engl J Med. 1999 Nov 11;341(20):1485-90. PMID:10559448

10. Green-Raleigh K, Carter H, Mulinare J, Prue C, Petrini J. Trends in folic Acid awareness and behavior in the United States: the Gallup Organization for the March of Dimes Foundation surveys, 1995-2005. Matern Child Health J. 2006 Sep;10(5) Suppl:S177-82. PMID:16823638

11. Bener A, Al Maadid MG, Al-Bast DA, Al-Marri S. Maternal knowledge, attitude and practice on folic acid intake among Arabian Qatari women. Reprod Toxicol. 2006 Jan;21(1):21-5. PMID:16112540

12. Jou HJ, Hsu IP, Liu CY, Chung SH, Chen SM, Gau ML. Awareness and use of folic acid among pregnant women in Taipei. Taiwan J Obstet Gynecol. 2010 Sep;49(3):306-10. PMID:21056316

13. Shawky RM, et al. Profile of genetic disorders prevalent in northeast region of Cairo, Egypt. Egypt J Med Hum Genet. 2012;13(1):45-62.

14. Samaha I, Rady M, Nabhan A, Gadallah M. The prevalence of congenital malformations at birth in Ain Shams University Maternity Hospital Cairo, Egypt, 1994. J Egypt Public Health Assoc. 1995;70(5-6):595-608. PMID:17214177

15. Cornel MC, Leurquin $P$, de Walle HE, Staal-Schreinemachers $\mathrm{AL}$, Beekhuis JR. Epidemiologie van prenatale diagnostiek en 
selective zwangerschapsafbreking vanwege foetale neuralebuisdefecten in Nederland in vergelijking met andere Europese landen [Epidemiology of prenatal diagnosis and selective pregnancy termination because of fetal neural tube defects in The Netherlands in comparison to other European countries]. Ned Tijdschr Geneeskd. 1997 Nov 15;141(46):2239-44. PMID:9550786

16. National Collaborating Centre for Women's and Children's Health. Antenatal care: routine care for the healthy pregnant woman (CG62). London: Royal College of Obstetricians and Gynaecologists Press; 2008.

17. Kalafatelis E, Fryer K. Awareness and knowledge of folate and folic acid: a survey of New Zealand women of child-bearing age. Wellinton, New Zealand: Ministry of Agriculture and Forestry; 2011.

18. Abdulrazzaq YM, Al-Gazali LI, Bener A, Hossein M, Verghese M, Dawodu A, et al. Folic acid awareness and intake survey in the United Arab Emirates. Reprod Toxicol. 2003 MarApr;17(2):171-6. PMID:12642149

19. Amitai $Y$, Fisher N, Haringman M, Meiraz H, Baram N, Leventhal A. Increased awareness, knowledge and utilization of preconceptional folic acid in Israel following a national campaign. Prev Med. 2004 Oct;39(4):731-7. PMID:15351539

20. Sharp GF, Naylor LA, Cai J, Hyder ML, Chandra P, Guillory VJ. Assessing awareness, knowledge and use of folic acid in Kansas women between the ages of 18 and 44 years. Matern Child Health J. 2009 Nov;13(6):814-21. PMID:18810617
21. Kari JA, Bardisi ES, Baitalmal RM, Ageely GA. Folic acid awareness among female college students: neural tube defects prevention. Saudi Med J. 2008 Dec;29(12):1749-51. PMID:19082226

22. Al-Hossani H, Abouzeid H, Salah MM, Farag HM, Fawzy E. Knowledge and practices of pregnant women about folic acid in pregnancy in Abu Dhabi, United Arab Emirates. East Mediterr Health J. 2010 Apr;16(4):402-7. PMID:20795424

23. An assessment of total costs and policy implications. In: Waitzman NJ, Scheffler RM, Romano PS, editors. The cost of birth defects: estimates of the value of prevention. Lanham (Maryland): University Press of America; 1996. pp. 145-77.

24. Williams LJ, Rasmussen SA, Flores A, Kirby RS, Edmonds LD. Decline in the prevalence of spina bifida and anencephaly by race/ethnicity: 1995-2002. Pediatrics. 2005 Sep;116(3):580-6. PMID:16140696

25. Centers for Disease Control and Prevention (CDC). Folate status in women of childbearing age, by race/ethnicity-United States, 1999-2000. MMWR Morb Mortal Wkly Rep. 2002 Sep 13;51(36):808-10. PMID:12269469

26. Mathews TJ, Honein MA, Erickson JD. Spina bifida and anencephaly prevalence-United States, 1991-2001. MMWR Recomm Rep. 2002 Sep 13;51 RR-13:9-11. PMID:12353510 